$\stackrel{1}{\Longrightarrow}$ Taylor \& Francis Online

Log in Register

\title{
Home
}

All Journals

African Journal of Science, Technology, Innovation and Development List of Issues

Volume 10, Issue 5

Applications of small-scale, stand-alone ....

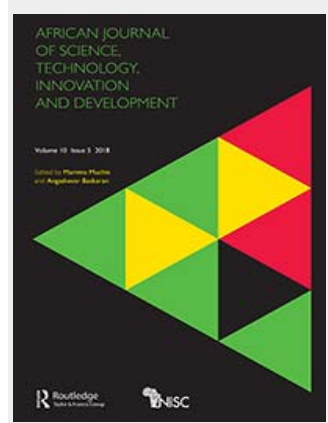

Search in:

African Journal of Science, Technology, Innovation and Development Volume 10, 2018 - Issue 5: Building low-carbon energy innovation systems in Africa Submit an article Journal homepage

\section{Applications of small-scale, stand-alone wind energy conversion systems in rural Cross River State, Nigeria}

Fidelis I. Abam (iD) \&Olayinka S. Ohunakin (iD)

Pages 539-550 | Published online: 19 Oct 2017

- Download citation

- $\quad$ https://doi.org/10.1080/20421338.2017.1366134

Select Language $\nabla$

$\underline{\text { Translator disclaimer }}$

- Full Article 
- Figures \& data

- $\quad$ References

- Citations

- Metrics

- Reprints \& Permissions

The study presents the wind energy potential (WEP) for six locations in Cross River State, Nigeria. The objective of the study was to assess the WEP of the selected sites for electricity generation, using small size wind energy conversion systems (WECs). The wind data were measured at $10 \mathrm{~m}$ height and ranged from 4 to 10 years. Additionally, the data were evaluated using the two-parameter Weibull function. Results obtained show that annual mean wind speed, $\mathrm{v}_{\mathrm{m}}$, and Weibull parameters $k$ and $c$ range from 3.21 to $4.55 \mathrm{~m} / \mathrm{s}, 3.32$ to 6.69 and 2.99 to $5.40 \mathrm{~m} / \mathrm{s}$, in that order. The cost per $\mathrm{kWh}$ of energy for the selected WECs fluctuated between $0.0626 \leq \mathrm{COE} \leq 0.1375 \mathrm{USD} / \mathrm{kWh}$, while the avoidable $\mathrm{CO}_{2}$ emissions exist between 0.64 and 38.21 tons/year. However, the probable savings made from diesel was not greater than 14,524.94 litres/year for the locations with high WEP for small-scale stand-alone applications.

Keywords:

wind energystand-alone $\mathrm{CO}_{2}$ emissionsWeibullCross River 